\title{
Packaging waste recycling in Europe. What is Romania's place?
}

\author{
Marian Zaharia \\ ${ }^{1}$ Association for Democracy, Education, Respect, Targu-Jiu, Romania \\ E-mail: marianzaharia53@gmail.com
}

\begin{abstract}
The imperative conditions for sustainable development both in Europe and around the world, waste collection is a fundamental goal, one way to achieve this is to develop circular economies. In this context, the paper analyzes the evolutions of the recycling rate of packaging waste by type of packaging in Romania compared to the 27 states of the European Union, as well as to other states in Europe. The analysis revealed that, among the 30 states included in the analysis, Romania moved from 28th place in 2006 to 23rd place in 2018, but is still quite far from the European Union average.

Keywords: wastes, packaging wastes, recycling, circular economy, Romania
\end{abstract}

\section{Introduction}

One of the imperatives of sustainable development and at the same time a practical way to achieve it is to move to a circular economy designed to increase the EU's competitiveness by protecting businesses from resource scarcity, creating new business opportunities and innovative ways [1]. An economy functioning as a sustainable ecosystem with integrated ecological and economic relations, which closes, reduces and tightens the resource loop [2], through appropriate entrepreneurial practices leading to the efficient use of resources and waste prevention, through actions aimed at reduce the amount of waste to be managed and treated by public authorities [3].

On the other hand, in market economies, with significant competitive processes, in the "visualization of products" and attracting consumers, the packaging of products plays an important role, packaging being the ones that attract attention. This leads to the search for and development of new forms and packaging techniques, targeting not only design but also environmental, logistical, waste management [4], whose production increases in parallel with that of the products for which they are intended, with an impact on management them. Under these conditions, a significant improvement in the collection of packaging waste is their design so as to make consumers aware of the recycling of specific packaging [5], through easy sorting and separation [6], and ultimately lead to a change in recycling behaviour of them [7].

Another important aspect of packaging recycling is the cost versus the benefits. Studies by Ferreira [8] have shown that industry should increase financial support for local authorities in this process, but if the benefits of avoiding other treatments are significant, the benefits outweigh the costs. Also viewed in terms of efficiency, Umarsman [9] presents a multi-criteria model for streamlining the management of the collection and separation of packaging waste, phases that he considers of prime importance in the recycling process. 
In Romania, packaging recycling management, although lasting for over a decade [10], is still partially solved with multiple revaluations and improvements, both in terms of infrastructure and in terms of legislation [11]. Willingly or unwillingly, Romania will have to align itself with European rigors [12] and increase the recycling rates of packaging waste not only to avoid possible sanctions, but also to move towards a 'circular economy'.

Taking into account the aspects presented above, the main objective of the paper was to analyze the evolution of the packaging waste recycling process, both in the Member States of the European Union, in its current structure, and in the non-member states for which data are available.

Taking into account the availability of data series, as well as to include as many states as possible in this analysis, the research covered the period 2006-2018. Thirty-one states were included in the analysis, the sample consisting of the 27 EU states, to which were added the United Kingdom, Iceland, Liechtenstein and Norway.

\section{Data series and methodology}

The main data source was the Eurostat database, respectively the data series on recycling rate of packaging waste by type of packaging [13].

The analysis included both data series on recycling rate of total packaging waste, and by types: paper and cardboard packaging, plastic packaging, wooden packaging, metallic packaging and glass packaging (Table 1). The recycling rate of packaging waste indicator is defined as the share of recycled packaging waste in all generated packaging waste [14].

Table 1. The variables used to analyze the evolutions of recycling rate of packaging waste

\begin{tabular}{llcl}
\hline Indicator & \multicolumn{1}{c}{ Significance } & Units & \multicolumn{1}{c}{ OBEs } \\
\hline TPR & Total packaging rate & $\%$ & \\
PCPR & Paper and cardboard packaging rate & $\%$ & \\
PPR & Plastic packaging rate & $\%$ & $\begin{array}{l}\text { exclusively material that is recycled back } \\
\text { into plastic }\end{array}$ \\
EPR & Wooden packaging rate & $\%$ & Including repair of wooden packaging waste \\
MPR & Metallic packaging rate & $\%$ & \\
GPR & Glass packaging rate & $\%$ &
\end{tabular}

In order to substantiate the performed analyzes, a series of statistical indicators were determined, among which means, despairs, regression coefficients, correlation ratios, determination coefficients, etc. The F test, the t test (Student) and the ANOVA methodology were used to test the statistical meanings of their values. The main statistical hypotheses are of the form:

$\mathrm{H}_{0 \_}$: parameter (mean, correlation coefficient) does not differ significantly from zero; it is not statistically significant $\left(t_{s}<t_{\alpha / 2, d f}\right)$.

$\mathrm{H}_{0 \_} 2$ : correlation ratio (coefficient of determination) does not differ significantly from zero; is not statistically significant ( $F_{S}<F_{\alpha, d f 1, d f 2}$ ).

In the null hypotheses above, $t_{s}$ and $F_{s}$ are the values of the statistics $t$ and $F$, determined according to the parameter whose value is to be tested in terms of statistical significance, $\alpha$ is the significance threshold, and $\mathrm{df}, \mathrm{df}_{1}$ and $\mathrm{df}_{2}$ represent the degrees of freedom.

The 95\% confidence coefficient $(\alpha=0.05)$ was used to test the statistical hypotheses. The processing of the data series corresponding to the six variables was performed using SPSS. 


\section{Results and discussions}

Packaging recirculation is not a new activity, it has older roots initially determined by economic considerations. The economic development and especially the forms of marketing have led to an increasing increase in the quantities of packaging waste becoming a pollution factor. This fact as well as the development of circular economies have led in recent decades to the development of their recycling management.

\subsection{An overview}

In a first phase, in order to have an overview of the transformations produced in the period 2006-2018 on the recycling rate of packaging waste, the characteristics of the data series corresponding to the six variables were determined and analyzed both at the beginning and at the end of the analyzed period.

At the level of 2006, the characteristics of the analyzed variables (Table 2) highlight the fact that, although the average values are statistically significant (statistical $t_{\text {calc }}<t_{0.025,25}=2.060$, rejecting the hypothesis $\mathrm{H}_{0_{-} 1}$ ), the values of variation coefficient lead to the conclusion that the data series corresponding to the variables PPR, WPR, MPR and GPR are not homogeneous, which means that there are big and very big differences between countries especially regarding recycling rate of wooden packaging waste and recycling rate of glass packaging waste. This conclusion is also underlined by the high values of the Range characteristic.

Table 2 Characteristics of the variables used, corresponding to 2006

\begin{tabular}{|l|r|r|r|r|r|r|}
\hline & \multicolumn{1}{|c|}{ TPR } & \multicolumn{1}{c|}{ PSPR } & \multicolumn{1}{c|}{ PPR } & \multicolumn{1}{c|}{ WPR } & \multicolumn{1}{c|}{ MPR } & GPR \\
\hline Mean & 50.03 & 69.20 & 25.56 & 29.54 & 57.56 & 56.64 \\
\hline Standard Error & 2.82 & 3.35 & 2.00 & 4.44 & 4.31 & 5.70 \\
\hline Median & 51.40 & 71.40 & 24.60 & 20.90 & 61.50 & 58.90 \\
\hline Standard Deviation & 15.21 & 18.05 & 10.78 & 23.50 & 23.23 & 30.72 \\
\hline Sample Variance & 231.20 & 325.73 & 116.11 & 552.41 & 539.46 & 943.44 \\
\hline Kurtosis & 0.31 & 2.49 & -0.77 & -0.60 & 0.29 & -0.96 \\
\hline Skewness & -0.43 & -1.15 & 0.00 & 0.71 & -0.58 & 0.07 \\
\hline Range & 68.20 & 83.00 & 39.80 & 77.10 & 93.80 & 107.60 \\
\hline Count* & 29 & 29 & 29 & 28 & 29 & 29 \\
\hline Confidence Level(95.0\%) & 5.78 & 6.87 & 4.10 & 9.11 & 8.83 & 11.68 \\
\hline \multicolumn{1}{c|}{$\mathrm{t}_{\mathrm{s}}$} & 17.72 & 20.65 & 12.77 & 6.65 & 13.35 & 9.93 \\
\hline $\mathrm{VC}$ & 0.30 & 0.26 & 0.42 & 0.80 & 0.40 & 0.54 \\
\hline
\end{tabular}

$\mathrm{t}_{\mathrm{s}}=$ Mean/ Standard Error; VC - variation coefficient

* at the level of 2006 for Croatia and Iceland no data were available

From the point of view of the type of distributions, it results that, except for PCPR for which Kurtosis has a value of 2.49>1.96, the others have normal distribution, TPR and MPR being leptocurtical and asymmetric on the right, and PPR, WPR and GPR are platicurtic and asymmetric on the left..

The data series corresponding to 2018 highlight the existence of several overall positive results. A first positive fact is the increase of the average values of all the six data series with values between 8.76 percentage points, in the case of the WPR variable, and 18.17 percentage points, in the case of the MPR variable, the values obtained being also statistically significant (statistics $t_{\text {calc }}<t_{0.025,30}=2.042$ ).

Another positive aspect is the increase of the homogeneity of the data series. The coefficient of variation (VC) values show that, with the exception of WPR, all other data series are homogeneous or 
relatively homogeneous. At the same time, the amplitude of the variation (Range) was reduced for four of the variables (TPR, PSPR, MPR and GPR), which means that the corresponding recycling rate of packaging waste trends tend towards average values, which is also highlighted by the reduction of Standard Error values. Standard Deviation and Sample Vaiance.

Table 3 The characteristics of the variables used, corresponding to 2018

\begin{tabular}{|c|c|c|c|c|c|c|}
\hline & $T P R$ & $P S P R$ & $P P R$ & $W P R$ & $M P R$ & $G P R$ \\
\hline Mean & 63.70 & 82.95 & 40.90 & 38.30 & 75.73 & 72.05 \\
\hline Standard Error & 1.67 & 2.08 & 2.13 & 3.80 & 3.21 & 3.51 \\
\hline Median & 65.70 & 82.90 & 37.70 & 30.00 & 77.60 & 75.15 \\
\hline Standard Deviation & 9.32 & 11.58 & 11.85 & 20.81 & 17.88 & 19.24 \\
\hline Sample Variance & 86.84 & 134.21 & 140.44 & 433.24 & 319.52 & 370.25 \\
\hline Kurtosis & 1.64 & 1.33 & -0.28 & 0.22 & 1.99 & -0.10 \\
\hline Skewness & -0.64 & 0.35 & 0.47 & 1.05 & -1.18 & -0.59 \\
\hline Range & 48.20 & 58.00 & 48.30 & 81.00 & 79.50 & 72.00 \\
\hline Count & 31 & 31 & 31 & 31 & 31 & 31 \\
\hline Confidence Level(95.0\%) & 3.42 & 4.25 & 4.35 & 7.77 & 6.56 & 7.19 \\
\hline $\mathrm{t}_{\mathrm{s}}$ & 38.06 & 39.87 & 19.22 & 10.08 & 23.59 & 20.51 \\
\hline $\mathrm{VC}$ & 0.15 & 0.14 & 0.29 & 0.54 & 0.24 & 0.27 \\
\hline
\end{tabular}

The values of the parameters of the shape of their distributions (Kurtosis and Skewness) and the data series corresponding to the six variables with a normal distribution were also improved.

Comparing the values of the parameters of the data series corresponding to the analyzed variables, it can be concluded that, overall, during the period 2006-2018, the recycling processes of packaging waste have improved, their recycling rate being higher.

\subsection{Evolutions of the recycling rate of total packaging waste process}

At the level of 2006, the first year for which the data series on recycling rate of packaging waste were available in most European countries, the values recorded were between 10.8\%, recorded in Malta, and $79 \%$, recorded in Belgium. At the level of the European Union, the recycling rate of total packaging waste was $56.8 \%$ (figure 1 ).

For the comparability of results and highlighting the performance of states in the analyzed period we structured the states included in the analysis, in terms of recycling rate of total packaging waste in three groups: the group of leaders (recycling rate over 65\%), the group of states with average performance (recycling rates between 55\% and 65\%) and, respectively, the group of low-performing states (recycling rate below 65\%).

The group of leaders in the recycling rate of total packaging waste in 2006 included five states, of which three (Belgium, Norway and the Netherlands) with recycling rate values above $70 \%$, and two (Austria and Germany) with recycling rate values of $68.4 \%$ and $66.5 \%$ respectively.

The group of states with average performance in recycling rate of total packaging waste included, in addition to the value recorded in the European Union (56.8\%), also five states. Of these, Luxembourg and the Czech Republic recorded values above 60.0\% (63.8\% and 63.4\%, respectively) while Sweden, UK and Denmark recorded values of recycling rates between 56.2\% (Denmark) and $58.1 \%$ (Sweden)..

The third group, the group of states with low performance in the recycling rate of total packaging waste was much more numerous, comprising 19 states. Of these, in 12 states the recycling rate values were between $40.3 \%$ (Slovenia) and 54.9\% (Italy), and in 4 states the recycling rate values were 
between $35.0 \%$ (Bulgaria) and $37.1 \%$ (Poland). The weakest performances in the recycling rate of total packaging waste were registered in Malta (10.8\%), Cyprus (25.2\%) and Romania (28.6\%)

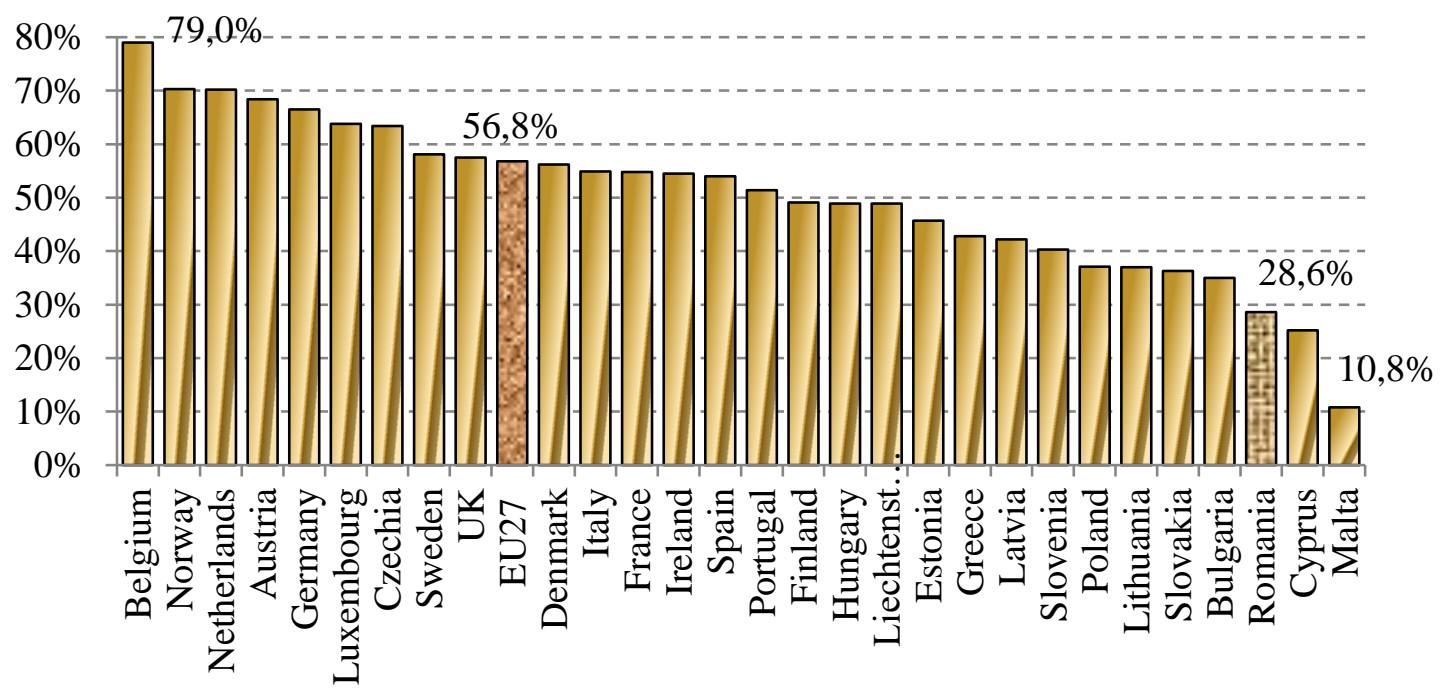

Figure 1 Recycling rate of total packaging waste în 2006

In the period 2006-2018, the process of recycling of packaging waste was characterized by an increase in intensity, both in the Member States of the European Union and in non-member states. Thus, in the case of the 27 states, currently members of the European Union, if in 2006 the difference between the highest and the lowest recycling rate was 68.6 percentage points, in 2018 , it decreased to 39.2 percentage points (Figure 2). The average values of the recycling rate of total packaging waste increased continuously, from $56.8 \%$, to $66.3 \%$, in 2018 , on an ascending train of 0.8 percentage points annually, for a level of uncertainty of $95 \%\left(\mathrm{R}^{2}=0.8502 ; \mathrm{F}_{\mathrm{c}}=62.43>\mathrm{F}_{0.05,1,11}=4.86\right)$

The leader, in the entire analyzed period, was Belgium, in which the rate of total packaging waste evolved on an ascending trend from 79.0\%, in 2006, to 85.3\%. in 2018.

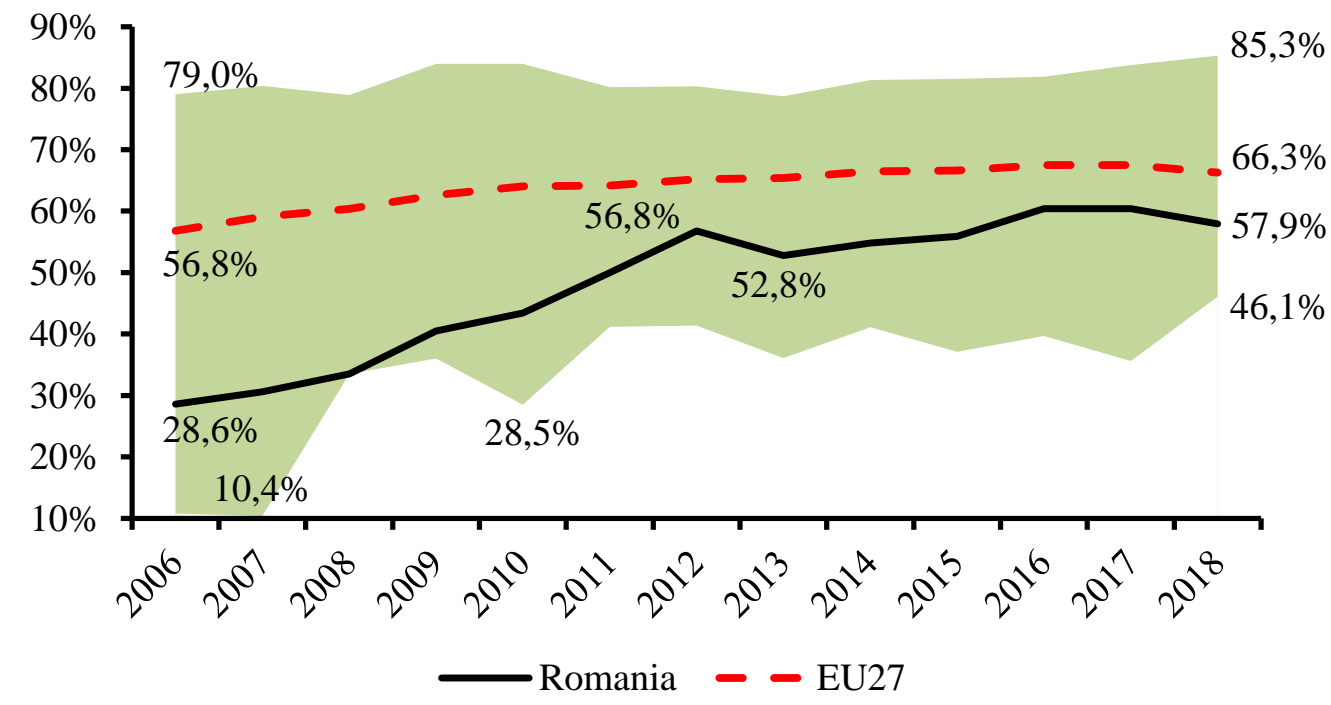

Figure 2 Evolution of recycling rate of total packaging waste in EU27 
At the opposite pole, the lower limit of the area of recycling values of total packaging waste was given alternately by Malta, (in 2006, 2007, 2009, 2010 and the period 2014-2017), Romania (33.5\% in 2008), Poland (2011-2013) and Hungary (46.1\% in 2018). It should be noted that the values of the lower limit of the recycling rate of total packaging waste fluctuated quite a lot, especially in the first half of the analyzed period (10.4\% in 2009, 36\% in 2009, $28 \%$ in $2010,41.4 \%$ in 2012).

In Romania, for the entire analyzed period, the evolution of recycling rate of total packaging waste was on an upward trend with an annual increase of 2.77 percentage points, statistically significant value for $\alpha=0.05\left(\mathrm{R}^{2}=0.8811 ; \mathrm{F}_{\mathrm{c}}=81.51>\mathrm{F}_{0.05 .111}=4.86\right)$. It should be noted that growth was stronger in the period 2006-2012, with an average annual increase of 4.7 percentage points. In 2013, the recycling rate of total packaging waste decreased by 4 percentage points (from $56.8 \%$ in 2012 to $52.8 \%$ in 2013). In the period 2013-2018 it returned to an ascending evolution with an average annual increase of 1.02 percentage points, so that in 2018 , the recycling rate of total packaging waste was $57.9 \%$.

In the case of non-EU Member States included in the analysis (Figure 3), the evolution of recycling rate of total packaging waste was both increased and decreased, so that, with the exception of Norway, the values recorded in 2018 were higher than those registered in 2006 and 2010 for Iceland, respectively.

In Norway, the data series shows a significant reduction in the recycling rate of total packaging waste very strong in the period 2006-2009, from $70.3 \%$ in 2006 to $53.1 \%$ in 2009 , followed by an oscillating period until 2018 , around a rate of $53 \%$.

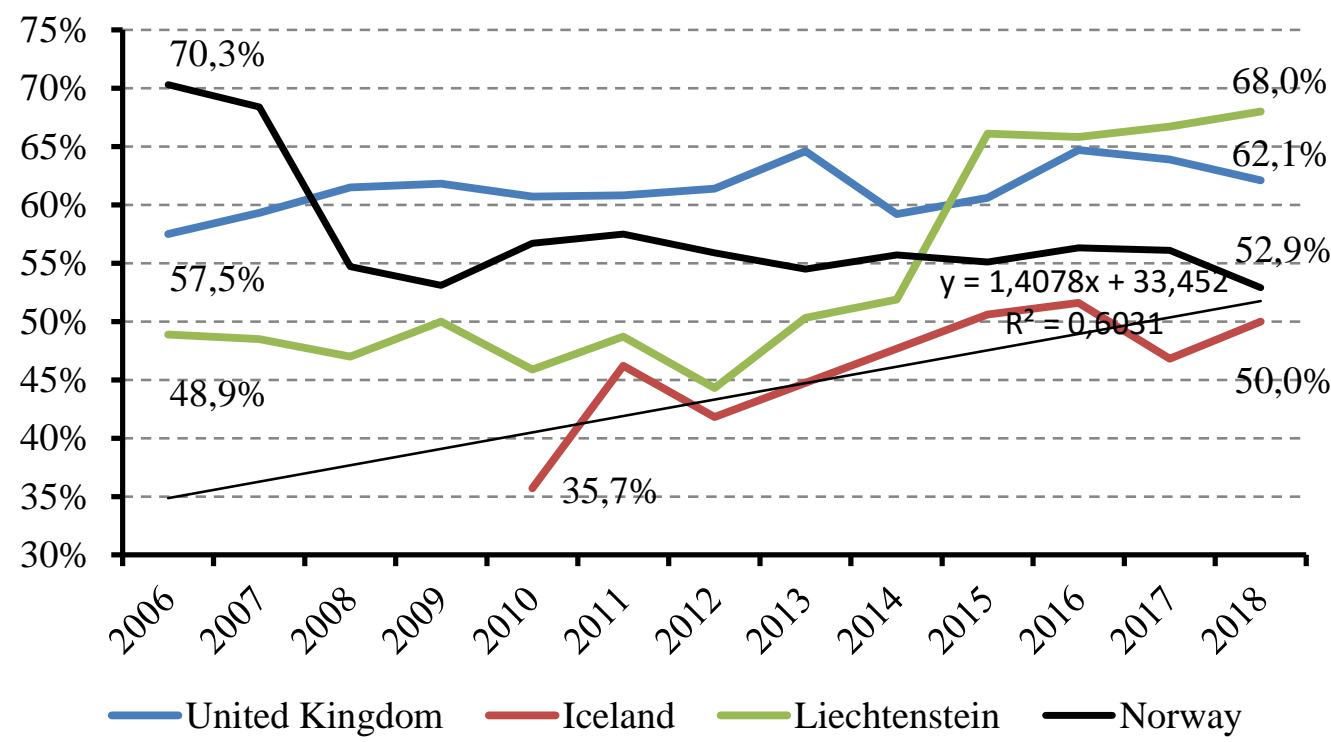

Figure 3 Evolution of recycling rate of total packaging waste in United Kingdom, Iceland, Liechtenstein and Norway

The evolutions registered by the recycling rate of total packaging waste, in the other three states, although they are increasing and differ significantly. Thus, in the United Kingdom the recycling rate of total packaging waste had an evolution that oscillated slightly around a trend with a very small slope, of 0.33 percentage points per year $\left(\mathrm{R}^{2}=0.374 ; \mathrm{F}_{\mathrm{c}}=6.56>\mathrm{F}_{0.05 .1}, 11=4.86\right)$. In contrast, in Liechtenstein the values recorded are characterized by large differences from one year to another which tends to stabilize on a slightly upward train after 2015. Overall, however, there is a significant increase of 19.1 percentage points. An evolution of a significant linear recycling rate of total packaging waste is also recorded in Iceland $\left(\mathrm{R}^{2}=0.6051 ; \mathrm{F}_{\mathrm{c}}=10.73>\mathrm{F}_{0.05,1,7}=5.58\right)$. significant of 19.1 percentage points. The slope of the regression line shows an annual increase of 1.41 percentage points. 
The evolutions of the recycling rate of total packaging waste, registered in the analyzed states, in the period 2006-2018, led to the restructuring of their ranking in the three performance groups defined above (Figure 4).

Thus, in 2018, the group of leaders in the recycling rate of total packaging waste consisted of 17 states. In first place is Belgium (85.3\%), followed by six states (Netherlands, Luxembourg, Slovenia Cyprus, Finland and Sweden) with recycling rate values between 70.1\% (Sweden) and 77.2\%

(Netherlands). The other 10 states recorded recycling rate values between 65.5\% (Austria) and 69.6\% Czech Republic.

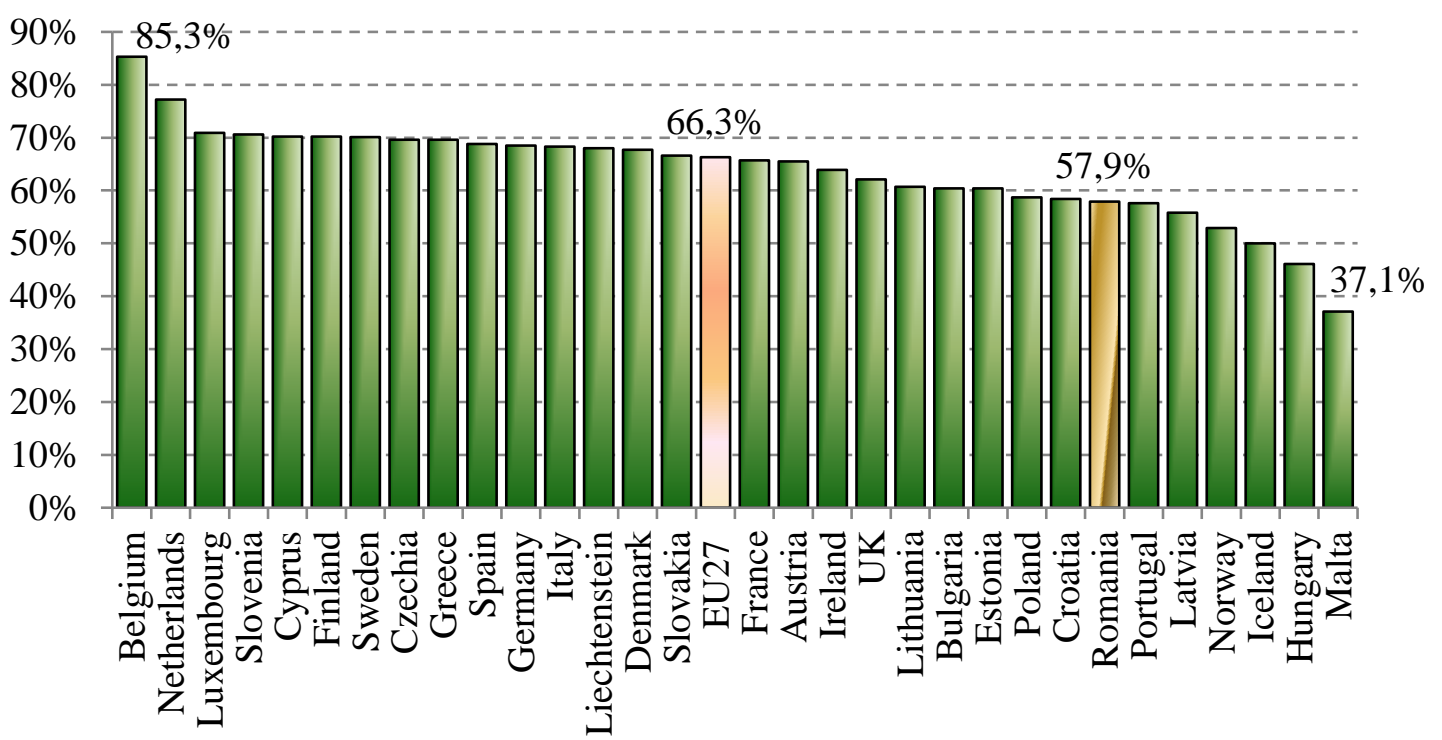

Figure 4 Recycling rate of total packaging waste în 2018

The progress made in the recycling rate of total packaging waste differs significantly from one state to another. The most significant increases were in Cyprus (45.0 percentage points), Slovakia (30.3 percentage points), Greece (26.8 percentage points), Finland (21.1 percentage points), Spain (14.8 percentage points), Italy (13.4 percentage points) and Frace (10.9 percentage points), states that passed from the third group (low performance group) directly to the group of leaders. It should be noted that, although it remained in the group of leaders, Austria recorded a decline in the recycling rate of total packaging waste of 2.9 percentage points (from $68.4 \%$ in 2006 to $65.5 \%$ in 2018).

Of the five states that in 2006 formed the group of states with average performance in recycling rate of total packaging waste, in 2028, only the UK remained, the others passing in the group of leaders. In 2018, in addition to the UK, eight more countries moved from this group to the third group, among which the most significant increases in recycling rates were registered in Romania (29.3 percentage points), Bulgaria (25.4 percentage points), Lithuania ( 23.7 percentage points), Poland (21.6 percentage points), Estonia (14.7 percentage points), and Latvia (13.6 percentage points). Also, in 2018 , Croatia is in this group with a recycling rate of total packaging waste of $58.4 \%$.

The third group, the group of states with low performance in the recycling rate of total packaging waste, decreased significantly, from 19 states in 2006 to 4 states in 2018: Norway (52.9\%), Iceland $(50.0 \%)$, Hungary $(46.1 \%)$ and Malta $(37.1 \%)$. Although Malta continues to be in last place among the states included in the analysis, it should be noted that in the period 2006-2018 it registered a significant increase of 26.3 percentage points in the recycling rate of total packaging waste. 


\subsection{Evolutions and mutations of the recycling rate of packaging waste by type of packaging}

Recycling rate of packaging waste differs significantly, both from one type of packaging to another, as compared to the recycling rate of total packaging waste. During the analyzed period, at the level of the European Union, the recycling rates by types of packaging had different evolutions (Figure 5) with values between $27.1 \%$ registered in 2006 for plastic packaging and $84.2 \%$, registered in 2018, for paper and cardboard packaging..

In the first place, in terms of recycling rates, in the entire analyzed period were paper and cardboard packaging waste. Their recycling rate increased from $75.4 \%$ in 2006, to $83.5 \%$ in 2012 and to $84.2 \%$ in 2018 , the total increase being 8.8 percentage points.

One of the lowest levels of recycling was recorded for plastic packaging and wooden packaging. Thus, in the case of plastic packaging, compared to a recycling rate of $27.1 \%$, which, in 2006, placed this type of packaging on the last place, in 2012, there was an increase of 9.9 percentage points, reaching $37.0 \%$, and in 2018 of $41.5 \%$, which, compared to 2006, represents an increase of $53.14 \%$. In the case of wooden packaging, the evolution of the recycling rate was totally different. If in the period 2006-2012 there was an increase of 2.6 percentage points, in the period 2012-2018 there was a decline of 3 percentage points, which led to a lower value of the recycling rate than in 2006 (34.5\%, in 2018, compared to $34.9 \%$ in 2006).

In the case of metal packaging and glass packaging, the values of recycling rates in 2018 were 1,218 times higher than in 2006. Recycling rate of metallic packaging fell from $68.1 \%$ in 2006 to $76.6 \%$ in 2012 (an increase of 8.5 points percentages) and to $82.9 \%$ in 2018 , which, in terms of recycling rates, ranks second. Regarding glass packaging, their recycling rate increased from $62.2 \%$ in 2006 to $73.1 \%$ in 2012 and $75.8 \%$ in 2018, the total increase being 13.6 percentage points.

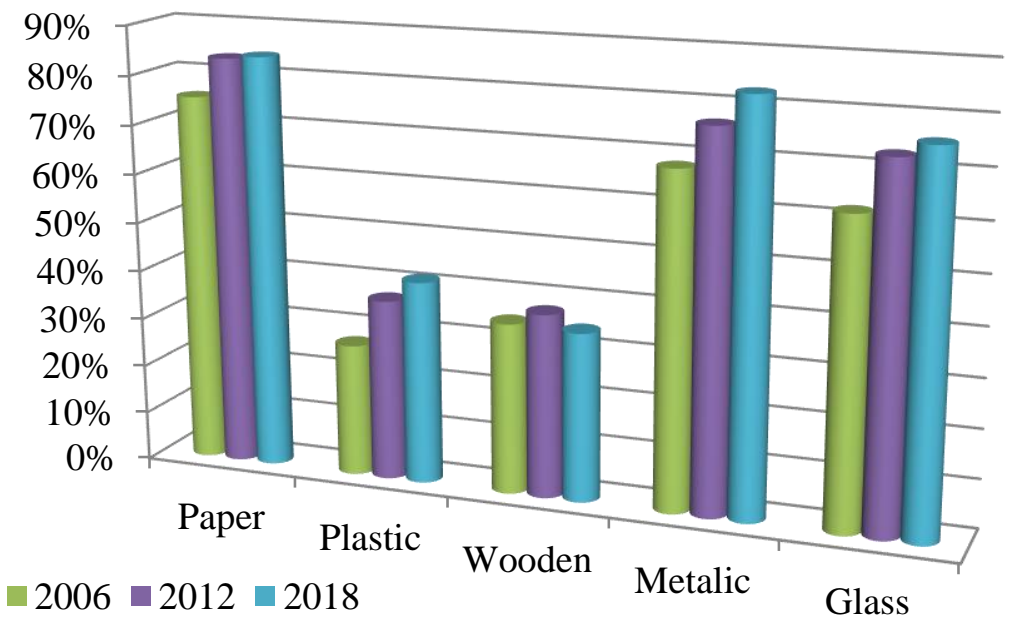

Figure 5 Recycling rate of packaging waste by type of packaging in EU27

At the level of Romania, both the increases and decreases in the values of recycling rate of packaging waste by type of packaging had higher amplitudes than those recorded in the European Union (figure 6), recycling rates by type of packaging evolving between 3.3\%, recorded value in 2006 for wooden packaging and $88.9 \%$, registered in 2018, for paper and cardboard packaging (value similar to that recorded at EU27 level)

The first place in terms of recycling rates was disputed by metallic packaging and paper and cardboard packaging. In the case of recycling rate of paper and cardboard packaging waste from a recycling rate of 55.7\%, which ranked it second in 2006 in this respect, after an increase of 14.1 percentage points, it reaches in 2012 in first place with a recycling rate of $69.8 \%$. The upward trend is still maintained, so that the recycling rate of paper and cardboard packaging waste reaches $88.9 \%$ in 2018. In contrast, the recycling rate of metallic packaging waste recorded, in the period 2006-2012, a decline of 21.7 percentage points, the recycling rate being only $55.5 \%$. In the period 2012-2018 the 
trend is reversed and following an increase of 3.2 percentage points, recycling rate of metallic packaging waste reaches $58.7 \%$, which places it in third place. Although plastic waste is particularly harmful to the environment, the recycling rate of plastic packaging waste in Romania has been at a low level. From a recycling rate of only $17.0 \%$ in 2006, in 2012 it reached $51.3 \%$, which is an increase of 34.3 percentage points. Unfortunately, in the period 2012-2018 there is a significant decline $(-8.3$ percentage points) so that in 2018 the recycling rate of plastic waste decreases to only $43.0 \%$.

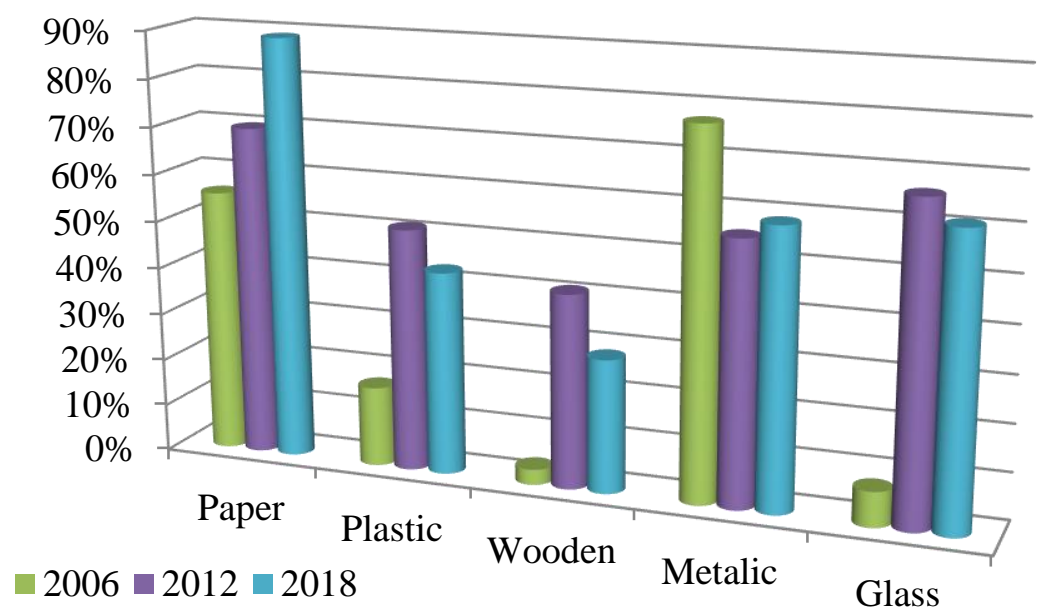

Figure 6 Recycling rate of packaging waste by type of packaging in Romania

In 2006, the lowest levels of recycling were recorded in wooden packaging and glass packaging. Thus, in the case of wooden packaging, compared to a recycling rate of $3.3 \%$, a value that, in 2006 , placed this type of packaging in last place, in 2012 there was an increase of 37.8 percentage points, reaching $41.1 \%$. As in the case of plastic packaging waste, in the period 2012-2018, there is a decline in the recycling rate of wooden packaging waste, so that in 2018 the recycling rate drops to $28.4 \%$, which corresponds to the last place.

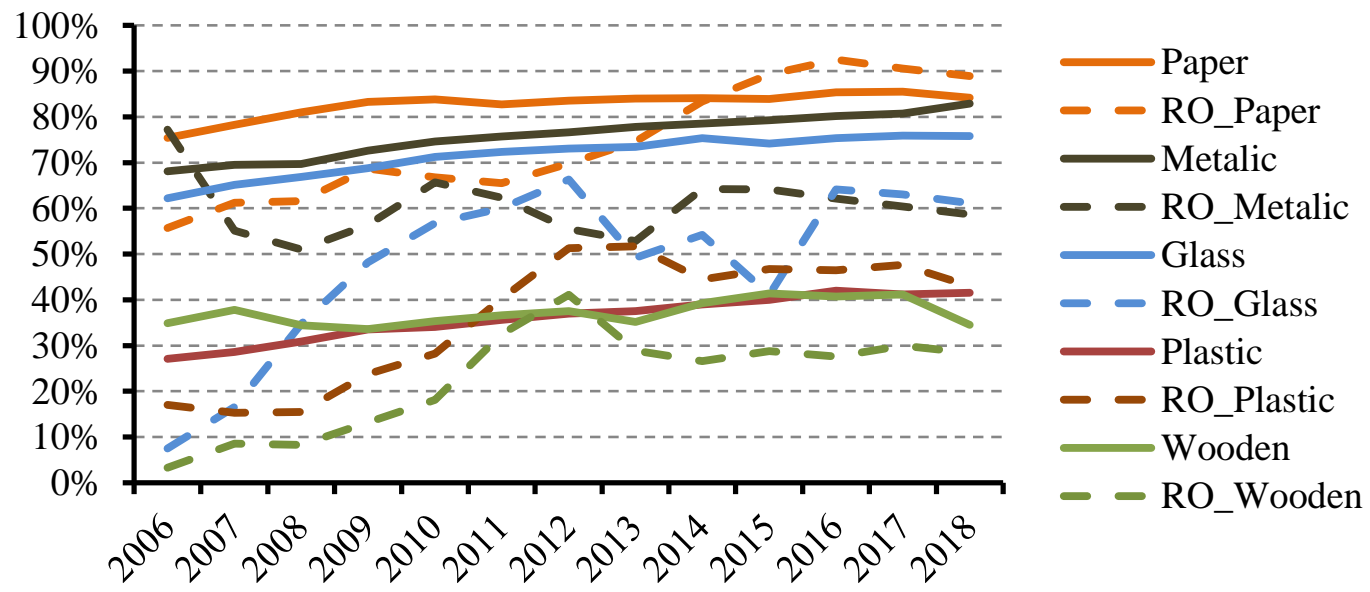

Figure 7 Comparative evolution of recycling rate of packaging waste by type of packaging in Romania and EU27

In the case of glass packaging, the evolution of the recycling rate was increasing in the period 2006-2012, registering an increase of 58.8 percentage points. In the period 2012-2018 there is also a decline (-5.2 percentage points), which led to a value of the recycling rate of $61.1 \%$.

For a more eloquent picture of Romania's position in relation to the European Union average in terms of recycling rate of packaging waste by type of packaging, Figure 7 shows in parallel the 
developments of recycling rates for each of the five types of packaging. In 2006, with the exception of the recycling rate of metallic packaging waste, which was 9.1 percentage points higher than the average registered in the European Union, in the case of other types of packaging, Romania was below average, with values between 10.1 percentage points, in in the case of plastic packaging, and 54.7 percentage points in the case of glass packaging.

The evolutions of the recycling rate of packaging waste from 2006-2012 lead to the reduction of the gaps, these being between 6.8 , in the case of glass packaging and 21.1 percentage points, in the case of metallic packaging. It should be noted that in 2012 the recycling rate of plastic packaging waste exceeded the European Union average by 14.3 percentage points, and the recycling rate of wooden packaging waste by 3.6 percentage points.

After sinuous evolutions, registered for all five types of packaging waste, in 2018, Romania registered values of recycling rate of packaging waste higher than the European Union averages for paper and cardboard packaging by 4.7 percentage points $(88.9 \%$, compared to $84.2 \%)$ and for plastic packaging with 1.5 percentage points $(43.0 \%$, compared to $41.5 \%)$. At the same time, values were lower than the European Union average for wooden packaging $28.4 \%$, compared to $34.5 \%$ (-6.1 percentage points), for glass packaging $61.1 \%$, compared to $75.8 \%$ (-14.7 percentage points), as well as for metallic packaging $58.7 \%$, compared to $82.9 \%$ (-24.2 percentage points).

\section{Conclusions}

During the analyzed period, the evolutions of the recycling rate values of total packaging waste registered in the 30 analyzed states were, with three exceptions, ascending so that, if in 2006 the lowest value of the total recycling rate was $10.8 \%$ (value registered in Malta), and the highest, of $79.0 \%$ (registered in Belgium), in 2018, they had reached $37.1 \%$ and $85.3 \%$ respectively, extreme values registered in the same states. Also, the European Union's average recycling rate of total packaging waste increased from 56.8\% in 2006 to 66.3 in 2018.

The evolutions of the recycling rate of total packaging waste were different from one state to another so that their hierarchical positions changed. The most significant increases, with over 25 percentage points were recorded in Cyprus (45.0 percentage points), Slovenia and Slovakia (30.3 percentage points), Romania (29.3 percentage points), Greece (26.8 percentage points), Malta (26.3 percentage points) ) and Bulgaria (25.4 percentage points). Small increases in the recycling rate of total packaging waste, below 10 percentage points, were recorded in Belgium, Czech Republic, Germany, Ireland, Luxembourg, Netherlands, Portugal and the United Kingdom. At the same time in Hungary, Austria and Norway there were decreases in the recycling rate of total packaging waste. These developments made Romania move from the penultimate place in 2006 (group of states with low performance on recycling rate of total packaging waste), in 2018, in the group of countries with average performance on recycling rate of total packaging waste.

The analysis performed on the recycling rate of packaging waste by type of packaging highlighted, in addition to the general trend of increasing recycling rates, significant differences between the five types of packaging. Thus, at the level of the European Union, from the point of view of recycling rate, in the period 2006-2008 there were increases in recycling rate of packaging waste to metallic packaging (14.8 percentage points), plastic packaging (14.4 percentage points), glass packaging (13.6 percentage points) and metallic packaging (14.8 percentage points), paper and cardboard packaging (8.8 percentage points), while the recycling rate of wooden packaging waste decreased by 0.4 percentage points. Under these conditions, in 2018, in terms of the value of recycling rate of packaging waste on the first place were paper and cardboard packaging $(84.2 \%)$, metallic packaging $(82.9 \%)$, glass packaging $(75.8 \%)$, plastic packaging $(41.5 \%)$ and wooden packaging $(82.9 \%)$.

In Romania, in the period 2006-2018, the evolutions of recycling rate of packaging waste by type of packaging were sinuous with increases and decreases of significant amplitudes. However, compared to 2006, when the gaps compared to the European Union average regarding the recycling rate of packaging waste of -54.7 percentage points for glass packaging and -31.6 percentage points for wooden packaging, in 2018, the largest gaps are recorded for metallic packaging (- 24.2 percentage 
points) and glass packaging (-14.7 percentage points). On the other hand, in 2018 , in Romania there were values of recycling rate of packaging waste above the European Union average for plastic packaging (with 1.5 percentage points) and paper and cardboard packaging (with 4.7 percentage points).

From the point of view of the place occupied in the European Union, in 2018, in terms of the values of recycling rate of packaging waste by type of packaging, Romania was on the 7th place for paper and cardboard packaging (with 88.9\%), on the 12th place plastic packaging (by 43.0\%), 17th place by wooden packaging (by 28.4\%), 23rd place by metallic packaging (by 58.7\%) and 19th place by glass packaging (by $61.1 \%$ ).

\section{References}

[1] European Commission (2015). Closing the loop - An EU action plan for the Circular Economy. Communication From The Commission to The European Parliament, The Council, The European Economic And Social Committee And The Committee of The Regions. https://eur-lex.europa.eu/legal-content/EN/TXT/?uri=CELEX:52015DC0614.

[2] Ilie, Margareta, Ilie, Constantin and Marin, Ruxandra, (2019), Management Strategies in Circular Economy, Ovidius University Annals, Economic Sciences Series, XIX, issue 2, p. 944949.

[3] Lucia-Monica, Scortar, (2013), STUDY ON PACKAGING WASTE PREVENTION IN ROMANIA, Annals of Faculty of Economics, 1, issue 1, p. 1404-1413.

[4] Wandosell, Gonzalo; Parra-Meroño, María C.;, Alcayde, Alfredo and Baños, Raúl, (2021), Green Packaging from Consumer and Business Perspectives, Sustainability, 13, issue 3, p. 1-19.

[5] Williams, Helén, Wikström, Fredrik, Wetter-Edman, Katarina and Kristensson, Per, (2018), Decisions on Recycling or Waste: How Packaging Functions Affect the Fate of Used Packaging in Selected Swedish Households, Sustainability, 10, issue 12, p. 1-19.

[6] Nemat, Babak, Razzaghi, Mohammad, Bolton, Kim and Rousta, Kamran, (2020), The Potential of Food Packaging Attributes to Influence Consumers' Decisions to Sort Waste, Sustainability, 12, issue 6, p. 1-22.

[7] Chen, Feiyu, Chen, Hong, Yang, Jiahui, Long, Ruyin and Li, Qianwen, (2018), Impact of Information Intervention on the Recycling Behavior of Individuals with Different Value Orientations-An Experimental Study on Express Delivery Packaging Waste, Sustainability, 10, issue 10, p. 1-20.

[8] Ferreira, S., Cabral, M., da Cruz, Nuno, Simões, P. and Marques, Rc, (2017), The costs and benefits of packaging waste management systems in Europe: the perspective of local authorities, LSE Research Online Documents on Economics, London School of Economics and Political Science, LSE Library.

[9] Umarusman, Talip Arsu Nurullah, (2020), Global Criterion Approach for the Solution of Multiple Criteria Data Envelopment Analysis Model: An Application at Packaging Waste Collection and Separation Facilities, Alphanumeric Journal, 8, issue 1, p. 79-96

[10] Sima, Cristian, (2012), Alternative systems for packaging waste collection, Revista de Economie Industriala (Journal of Industrial Economics), 10, issue 1, p. 21-30.

[11] Jora, Octavian-Dragomir, Patruți, Alexandru and Iacob, Mihaela, (2018), The Vicious Circles of Bureaucratic Circular Economy: The Case of Packaging Waste Euro-Targets for Romania, The AMFITEATRU ECONOMIC journal, 20, issue 48.

[12] Teodor, Cristian, Trica, Carmen Lenuta, Ignat, Raluca and Dracea, Raluca-Mihaela, (2020), Good Practices of Efficient Packaging Waste Management, The AMFITEATRU ECONOMIC journal, 22, issue 55.

[13] https://ec.europa.eu/eurostat/databrowser/view/cei_wm020/default/table?lang=en. Recycling rate of packaging waste by type of packaging [cei_wm040]

[14] https://ec.europa.eu/eurostat/cache/metadata/en/cei_wm020_esmsip2.htm 